Professor Sellers's book brings together various loosely connected topics which are not at present available in English. His writing is clear and economical, and the bibliography is up to date. The book is strongly recommended to students, but it should also be very useful to many meteorologists.

R. Murray

\section{HISTORY FOR SCIENTISTS}

\section{Chymia}

Annual Studies in the History of Chemistry, Vol. 10. Edited by Henry M. Leicester. Pp. 258. (Philadelphia: University of Pennsylvania Press; London: Oxford University Press, 1965.) 40s. net.

Chymia, the tenth in the series of annual publications, contains the following articles: "How Old is Hydrochloric Acid ?", by L. Reti; "Christophle Glaser and the Traité de la Chymie, 1663", by R. G. Neville; 'Berthol let, Proust, and Proportions", by S. C. Kapoor; "Unpublished Letters from H. Sainte-Claire Deville to B. S. Yakobi", by Y. I. Solov'ev; "Induced Oxidationreduction Processes, the History of a Chemical Paradox", by E. Farber; "A Precursor of the American Chemical Society-Chandler and the Chemical Society of Union College", by E. K. Bacon; "Historical Sketch of the Electron Theory of Organic Chemistry", by G. V. Bykov.

Tho criteria for judging this book are provided by the publishers in a statement on the dust-cover: "The publication of scientific literature has reached such vast proportions in recent decades that the specialist is hard pressed to keep up with developments even in his own limited field. The history of science is thus largely neglected in favour of current findings and it has become increasingly difficult for the reflective scientist to maintain a sense of development, over centuries, of his area of study. Chymia is an attempt to supply, in the field of chemistry, information necessary to this perspective".

With the exception of those by Solov'ev and Bykov (the latter is excellent, and will greatly interest physicists as well as chemists) the articles show no evidence of having been written to provide interesting perspective for reflective scientists. The reason that the hard-pressed specialist neglects the history of scienco in favour of recent findings is that this book is the sort of material that he is offered by the historians. It is specialist, pedantic history written for a diminishing circle of specialist, podantic historians. Do the publishers really believe

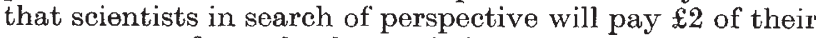
own money for a book consisting mainly of long and obscure accounts of historical niceties adorned with the familiar archaic trappings so beloved by venerable scholars (untranslated passages of Latin, reproductions of the title pages of old books, hundreds on hundreds of footnotes, the main purpose of which seems to be to demonstrate that the authors have access to well-stocked libraries) ?

If science historians are genuinely concerned about being neglected they must make an effort to present articles that will stimulate and interest scientists who are not historians. They must interpret the past; they must, as Bykov does so well, relate the past to the present. It is not enough to write in detail about the past and expect non-historians to be interested simply because the events described happened long ago, or to describe rare books and expect interest simply because the books are rare. If, on the other hand, they are oblivious to neglect by non-historians (which I suspect to be the truth) they will continue to ignore their important role as interpreters and will continue to write articles like these for each other to read. This is fine-scholarship for its own sake is a necessary human activity, and an enjoyable one-but if the scholar ignores society, he has no right to complain if socicty ignores the scholar.

\section{MEN OF STEEL}

\section{The Sorby Centennial Symposium on the History of Metallurgy}

Cleveland, Ohio, October 22-23, 1963. Edited by Cyril Stanley Smith. (Metallurgical Society Conferences, Vol. 27.) Pp. xxii +558 . (New York: Gordon and Breach; London and Glasgow: Blackie and Son, Ltd., 1965.) $156 s$.

IN this, thirty-six authors from six countries combine to cover in thirty-three chapters the lives of a number of pioneers of metallurgical science technology and techniques and the history of a variety of metallurgical phenomena, methods and theories mainly relating to iron and steel. The mass, or more correctly the volumes, of technical literature with which scientists and technologists are faced today is physically burdensome and mentally overwhelming since almost by definition most worthwhile books require sustained concentration if their reading is to be effective. The contents of the chapters of this centennial tribute by three American societies, principally to H. C. Sorby and other English metallurgists, can be read in relaxed fashion and the chapters, which are largely unconnected with each other, can be taken up at random.

The chapters divide into four groups of different interests-people, phenomena, techniques, particularly metallography and ferrous based materials. As would be expected of so many authors, the style, approach and readability are variable. If generalization is possible, the chapters about people-those individuals who initiated and brought some metallurgical feature to successful fruition-are composed like curriculum vitae, factually incontrovertible but a dull method of presentation; in support one can cite the chapters on J. F. Stead and J. O. Arnold and even the autobiographical chapters by Z. Jeffries and E. C. Bain.

The chapters I most enjoyed, because of the sense of participation in and the feeling of association with the events they describe, were related to phenomena (or lack of them). Today, scientific literature is written in a formalized impersonal fashion". But "The $\beta$-iron Controversy" as reported by M. Cohen and J. M. Harris (and the mysterious "jargonium" of Sorby, pp. 37 and 38), "Dislocations in Plasticity" by E. Orowan, "History of Precipitation Hardening" by H. Y. Hunsicker and H. C. Stumpf and "The Development of the Theory of Alloys" by W. Hume Rothery, all had a personal imprint of their authors' sense of excitement. And where individuals write of their own contributions to metallurgical history, it is interesting to compare the introverted, factual, succinct description of the "Note on the Early Stages of Dislocation Theory" by G. I. Taylor with the extroverted exuberant expansive but still factual account of the Hungarian, E. Orowan. These differences lend a great deal of colour as well as surprise to the book.

The early history of metallography and the advanced level to which the technique was brought by Sorby and others should induce humility in the reader and practitioners of the method.

The descriptions of the development of materials"Iron Manufacture in Britain in the Decade 1850-60", "History of Silicon-iron", "Soft Magnetic Materials", "Tungsten" and "Powder Metallurgy in Development of Dispersion-hardened Materials"--are interesting in that they show some kind of order in the history of the development of these materials even although to the individuals who lived through these developments the successive improvements were achieved in spite of a confusion of facts and misconceptions. It would be pleasing to be able to say that all future developments in metallurgy will be made without having to go through the same bewilderments that faced the several pioneers in this volume, but if this book teaches anything it is that trial and error-with emphasis on the error-is the likeliest way for future developments. 